\title{
Impact of Roadside Fixed Objects in Traffic Conditions
}

\author{
Nabil Hazim \\ Department of Civil Engineering \\ Al-Ahliyya Amman University \\ Amman, Jordan \\ n.hazim@ammanu.edu.jo
}

\author{
Lina Shbeeb \\ Department of Civil Engineering \\ Al-Hussain Technical University \\ Amman, Jordan \\ lina.shbeeb@htu.edu.jo
}

\author{
Zaydoun Abu Salem \\ Department of Civil Engineering \\ Applied Sience Private University \\ Amman, Jordan \\ z_abusalem@asu.edu.jo
}

\begin{abstract}
Highway Capacity Manual (HCM) assumes that traffic flow rates are equally distributed between lanes, which is not always the case. Lane distribution and speed are influenced by lateral clearance on the roadsides. In Jordan, the absence of wellmarked lanes and poor lane discipline results in under-utilizing of the freeway capacity. The objective of this study is to look into the impact of the presence of roadside objects on lane distribution and speed. Test sections were selected on six-lane freeway segments located in sub-urban areas on tangent highway segments. Speed measurements and distribution counts made for each lane on a directional three-lane segment of the freeway. The results showed that lane distribution significantly varies depending on lateral clearance and traffic. As lateral displacement increases, right-lane-use and left-lane-use increases while the middle-lane use remains almost at the same level. Average speed increases as the lateral clearance increases. The results also showed that average speed and lane distribution for $1.5 \mathrm{~m}$ lateral clearances are very similar to no obstacle conditions. The impact of an obstacle is more significant on the right lane while the use of the left lane fluctuates with a significant increase if traffic flow rates reach high levels.
\end{abstract}

\section{Keywords-lane distribution; obstacle; speed}

\section{INTRODUCTION}

Traffic lane distribution in freeways consist an important parameter regarding traffic, which receives considerable attention. HCM assumes that traffic flow rates are equally distributed between lanes, which is not always the case, particularly at low traffic flow rates. Other factors may influence lane distribution and average speed, including lateral clearance. Lateral clearance is defined as an obstacle free area beginning at the edge of travel lane and extending to a minimum distance such that it does not interfere with the operation of the roadway. In Jordan, the absence of wellmarked lanes and the poor lane discipline result in underutilizing of the freeway capacity. There is a need to understand traffic behavior by a detailed simulation model, by giving important inputs (headway time and vehicular speed). The lane flow-distribution can directly influence the capacity of the freeway section under investigation, and in the presence of high volumes, more vehicles travel on the median lane rather than on the shoulder lane [3, 5-7, 10-15].
In [7], the distribution of the total traffic flow in individual lanes was derived mathematically. Two-lane and three-lane carriageways were studied. The frequency of lane changing was also considered. Unfortunately, the mathematical derivation in his work contains a minor error, although this does not significantly affect the numerical results. The flowdistribution in individual lanes is re-derived and extended to carriageways with more than three-lanes. The model is then calibrated with field data obtained from Germany. Authors in [14] investigated the impact of a median barrier on mean traffic speeds on selected sites with passed speed zones of $70 \mathrm{~km} / \mathrm{h}$ and $80 \mathrm{~km} / \mathrm{h}$. The findings suggested that mean speed on section with barriers was actually higher than the base free flow speed along road section without barriers. Authors in [17] stated that aggressive driving and infringement of traffic laws and regulations were noticed to be the main factors of road traffic accidents in Saudi Arabia and that road conditions or objects on roads had minor effects. Authors in [1] reported that on-street parking can create stop-start traffic flow behavior for the lanes adjacent to the parking lane affecting the capacity of the road section and any obstacle vision on the road located closer than $1.8 \mathrm{~m}$ from the edge of traffic lane means that lateral clearance is not ideal and therefore the road capacity will be reduced. Also they reported that the road capacity value drops due to various "non-ideal conditions" including changes in speed or travel time, traffic interruptions or restrictions. Authors in [4] show that a solid barrier induces an updraft motion and lofts the vehicle emission plume. Author in [8] discussed the capacity and quality of service of two-lane highways and defined some of the factors that affect the capacity such as heavy vehicle presence, lane width, and lateral clearance and reported about the weather and road capacity and discussed how the weather affects the capacity and the extent of the proportion of influence in different situations. Authors in [12] investigated lane utilization by vehicle type. A study on four lane-two way and six lane-two way highways showed that light vehicles and heavy vehicles were using the middle lane, whereas most motorcycles were using the curb lane or the middle lane.

Authors in [13] investigated both lane density and lane flow distribution on freeways with ITS systems. Two concepts were introduced: lane flow distribution ratio and the land density distribution ratio to resemble factors for congestion estimation. 
Authors in [17] indicated that traffic volume on a major road is a significant predictor of crashes at un-signalized intersections and the geometric characteristics and features of un-signalized intersections have also been found to be potential explanatory variables in crash prediction models. Authors in [11] investigated speed distribution profile by considering vehicle types and analyzed time headway distribution profiles for different vehicle types at five different traffic densities ranging from 0 to $80 \mathrm{PCU} / \mathrm{km}$ with an increment of $20 \mathrm{PCU} / \mathrm{km}$.

Lane flow-distribution is different from country to country. The difference can be attributed to the prevailing laws and regulations and the associated level of enforcement and road user behavior. For example, the typical shape of lane flowdistribution on German motorways is a consequence of the strict regulations of "commandment of driving on the right" and "prohibition of overtaking on the right". In general, the country-related lane flow distribution should be investigated further.

\section{StUdy OBJective}

This study investigates the impact of the presence of roadside objects on traffic parameters such as lane distribution and speed. The study attempts to define obstacle's clearance that would minimize its impact on traffic parameters.

\section{COLLECTION OF FIELD DATA OBSERVATIONS}

Lane distribution counts and speed measurements were made at four-lane and six-lane test sites in the spring of 2019. The counts begun at 11 am on March 9, 2019 and continued in an hourly basis for the duration of one week (to $1 \mathrm{am}$, March 16, 2019). The choice of the starting date was considered unimportant as long as no major changes in the traffic flow were anticipated. For this reason, the counts and speed measurements were not made during holidays. The procedure for collecting lane distribution data and speed measurements consisted basically of observing the lane of choice for each vehicle passing the test sites. Lane distribution counts were made at the test sites in quarter hourly intervals beginning at the start of each hour. Lane distribution data and speed measurements were recorded for a particular test site, direction of travel on a data sheet prepared for the purpose. Because of the large number of vehicles anticipated at the test sites, counters were used for recording vehicle repetitions by lane. At the end of each hour, the counter readings were transferred on the data sheets, the counters were zeroed, and a new set of sheets were initiated for the next time period. This procedure was repeated throughout the testing period. Four locations for placing obstacles were selected varying in half meter intervals starting from the edge of the travel lane (zero distance). The test sections were $30 \mathrm{~m}$ long and the lateral clearances were formed by placing a series of traffic cones spaced in $0.3 \mathrm{~m}$ intervals. Data were also collected for the same sections but without obstacles.

Test sections were selected on six-lane freeway segments with fully controlled access located in sub-urban areas along Queen Alia International Airport Highway in Amman District (Figure 1). These sites were chosen so that there would be no influence from lateral restrictions as access ramps, grade separation structures, traffic signs, and (or) rest areas. The test sites were located on long-tangent highway segments. The tangent distances from the horizontal curves are of sufficient length so that the lane distributions at the test site were not affected by these curves. Lane distribution counts made for each lane of the directional three-lane segment. The grade and rate of vertical curvature are minimal throughout the tangent length (geometric design criteria stipulate a minimum slope for drainage purposes). The three-lane test sections were located reasonably near each other so that the traffic streams observed at all test sites were nearly identical. There is a suitable observation point at each test site for the data collectors with good visibility of the traffic while providing maximum concealment of the data collection operation.

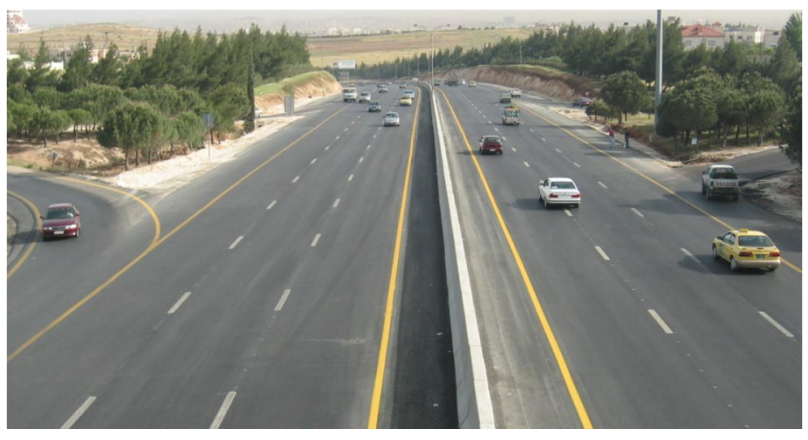

Fig. 1. Test section on Queen Alia international airport highway

The cross sections of the highway at the test sites are typical of that constructed along the entire highway length. The pavement surface characteristics are consistent, with respect to appearance and roughness for all lanes and along the entire highway length. Striping is distinct and properly positioned on the roadway. Finally, the physical conditions of the shoulders and medians were sufficient.

\section{ANALYSIS METHODOLOGY}

The fifteen-minute-counts were converted to hourly traffic flow (qsum). Given the total flow rate of a freeway, qsum, the relationship between the proportion of traffic flow rates, $\mathrm{p} 1, \mathrm{p} 2$, and $\mathrm{p} 3$ on the right, middle and left traffic lane respectively, can be calculated as a function of the total flow rate qsum. Hence, the following relationships always hold: $P 1=q 1 / q s u m$, $\mathrm{P} 2=\mathrm{q} 2 / \mathrm{qsum}, \mathrm{P} 3=\mathrm{q} 3 / \mathrm{q}$ sum, and $\mathrm{P} 1+\mathrm{P} 2+\mathrm{P} 3=1$, where $\mathrm{q} 1, \mathrm{q} 2$, and $\mathrm{q} 3$ are traffic flow rates for right, middle, and left lane respectively $[2,9,16]$. The generalized procedure selected as most applicable for analyzing the lane distribution data taken in this study consisted of descriptive analysis including graphical presentation describing lane distribution versus traffic volume for each tested site, each obstacle location and comparison with the no obstacle case. Inferential tests were conducted to detect what would be the impact of lateral clearance on some traffic parameters (lane distribution and speed). F-test and paired sample t-tests were used for the analysis.

\section{ANALYSIS RESULTS}

Table I represents a summary of the results of this study. It shows that lane distribution differs by obstacle distance (lateral clearance) from the carriageway edge and traffic flow rates. 
However, the overall average suggests small difference in lane use proportion as a function of directional traffic flow that can be explained by lateral clearance. It seems that in Jordan, drivers tend to be more aggressive while approaching obstacles. They normally would force their way in and thus a variation in the findings of this research and those of other studies can be explained. The variation of the lane distribution is related to lateral clearance (the distance of the obstacle measured from the travel-lane edge) as indicated in Figure 2. The average lane distribution changes with the lateral clearance $(0 \mathrm{~m}, 0.5 \mathrm{~m}, 1.0 \mathrm{~m}$, and $1.5 \mathrm{~m})$.

TABLE I. LANE DISTRIBUTION BY TRAFFIC FLOW AND LATERAL CLEARANCE

\begin{tabular}{|c|c|c|c|c|c|c|c|c|c|c|c|c|c|c|c|}
\hline \multirow{2}{*}{$\begin{array}{l}\text { Hourly traffic } \\
\text { flow (veh/h) }\end{array}$} & \multicolumn{3}{|c|}{$0.0 \mathrm{~m}$} & \multicolumn{3}{|c|}{$0.5 \mathrm{~m}$} & \multicolumn{3}{|c|}{$1.0 \mathrm{~m}$} & \multicolumn{3}{|c|}{$1.5 \mathrm{~m}$} & \multicolumn{3}{|c|}{ No obstacles } \\
\hline & Right & Middle & Left & Right & Middle & Left & Right & Middle & Left & Right & Middle & Left & Right & Middle & Left \\
\hline 800-1199 & 0.20 & 0.40 & 0.39 & 0.19 & 0.43 & 0.37 & 0.21 & 0.42 & 0.38 & 0.23 & 0.41 & 0.36 & 0.26 & 0.37 & 0.37 \\
\hline 1600-1999 & 0.22 & 0.39 & 0.39 & 0.28 & 0.37 & 0.35 & 0.26 & 0.40 & 0.34 & 0.26 & 0.40 & 0.33 & 0.27 & 0.41 & 0.32 \\
\hline 2000-2399 & 0.23 & 0.34 & 0.43 & 0.29 & 0.34 & 0.37 & 0.27 & 0.35 & 0.38 & 0.27 & 0.37 & 0.36 & 0.25 & 0.34 & 0.41 \\
\hline Average & 0.21 & 0.39 & 0.39 & 0.25 & 0.39 & 0.36 & 0.23 & 0.41 & 0.37 & 0.25 & 0.39 & 0.35 & 0.25 & 0.40 & 0.35 \\
\hline
\end{tabular}
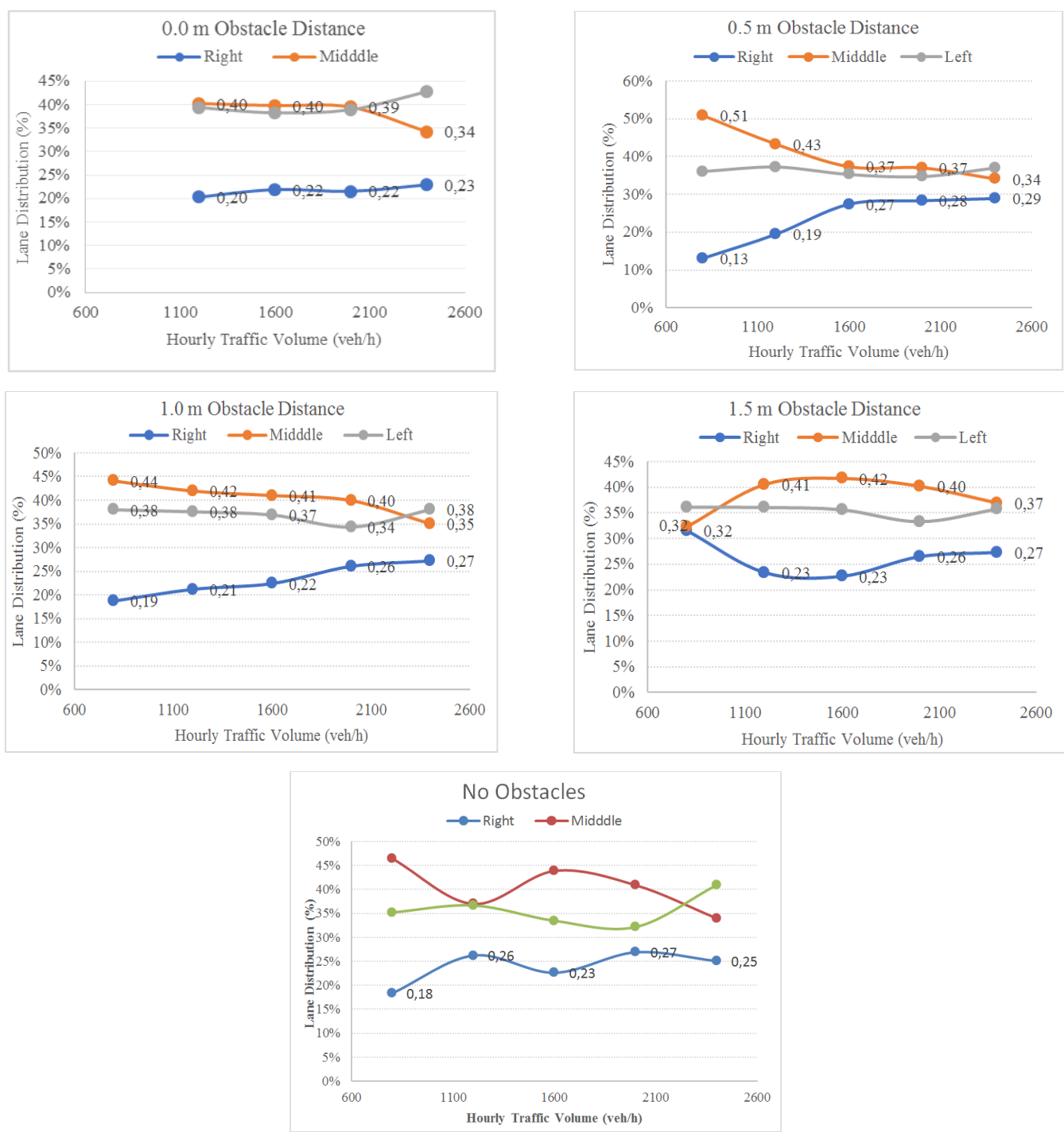

Fig. 2. Average lane distribution change with lateral clearance $(0 \mathrm{~m}, 0.5 \mathrm{~m}, 1.0 \mathrm{~m}, 1.5 \mathrm{~m}$ and the no obstacle)

At high traffic flow rates, the use of the middle lane decreases while the use of the right lane increases. The uses of left-lane marginally differ by traffic flow rate magnitude except when traffic flow rate reaches 2000 vehicles per hour (veh/h). Figure 2 suggests that the same pattern of traffic lane distribution is noted for lateral clearance less than or equal to 1 , 
but not the magnitude. For instance, right lane use starts to increase as traffic volume increases, but the difference between its use when the traffic flow rate is low and when it is high is more profound when the distance to travel lane edge is $0.5 \mathrm{~m}$. Right lane use tends to stabilize when flow rate exceeds or is equal to $1,600 \mathrm{vel} / \mathrm{h}$ when the obstacles are placed $0.5 \mathrm{~m}$ from the travel lane edge and increases to $2,000 \mathrm{veh} / \mathrm{h}$ for $1 \mathrm{~m}$ distance. Figure 2 also suggests that generally a similar trend of lane distribution is observed between a distance of $1.5 \mathrm{~m}$ and the no obstacle case with some exceptions related to traffic flow rate less than or equal to $1,200 \mathrm{veh} / \mathrm{h}$. If the obstacles are placed at $1.5 \mathrm{~m}$ from the travel-lane's edge, the distribution of traffic flow rate over the three lanes is, to some extent, similar to the distribution related to the no-obstacle case. The similarity is more obvious for left-lane use. It decreases with the increase of low traffic flow rate, but for high traffic, it increases. Rightlane use is high at low flow rate and then it decreases until it reaches a level of $1600 \mathrm{veh} / \mathrm{h}$ where it starts to increase. The trend of middle-lane-use is opposite of the right-lane use. It starts low and increases up to $1600 \mathrm{veh} / \mathrm{h}$ where its starts to decrease. For the no-obstacle case, the lane-use distribution fluctuates with no clear pattern, except the left lane use as explained above.

The statistical analysis shown in Figure 3 indicates that inlarge and with few exceptions, there is no significance difference in lane distribution that could be explained by lateral clearance. Significant difference is mainly associated with the right-lane-use for traffic flow rate over $800 \mathrm{veh} / \mathrm{h}$. As indicated above, left-lane-use follows a similar trend for different traffic flow rates but not when it reaches high level (2000-2399veh/h). The statistical analysis proves that there is a significant difference that could be explained by obstacle location. Rightlane-use differs significantly by obstacle location. The difference is higher at low traffic flow rates and tends to decline at higher traffic flow rates (Figure 4). Middle-lane uses also differ according to obstacle locations for all traffic flow categories but not for the highest level $(2400 \mathrm{veh} / \mathrm{h})$. The difference is either statistically significant or marginally significant. No significant difference of left-lane-use distribution has been reported for all traffic categories, except at high traffic flow rate $(2400 \mathrm{veh} / \mathrm{h})$. A further look into lane distribution as a function of flow rate, shows that there is significant difference in right lane use $(\mathrm{F}=6.626, \mathrm{P}=0.000)$. Figure 5 shows that as traffic flow rates increase the right-laneuse increases. On the other hand, as traffic flow rates increase, the use of middle-lane-use decreases with significant difference $(\mathrm{F}=7.283, \mathrm{P}=0.000)$. The left-lane-use marginally fluctuates with significant difference $(\mathrm{F}=3.792, \mathrm{P}=0.006)$. Data was aggregated by averaging lane distribution for all traffic flow rates for each obstacle location as given in Figure 5. It suggests that right lane use increases with increase of the lateral clearance. There is significant difference in right-lane use due to obstacle location $(\mathrm{F}=4.339, \mathrm{P}=0.002)$.

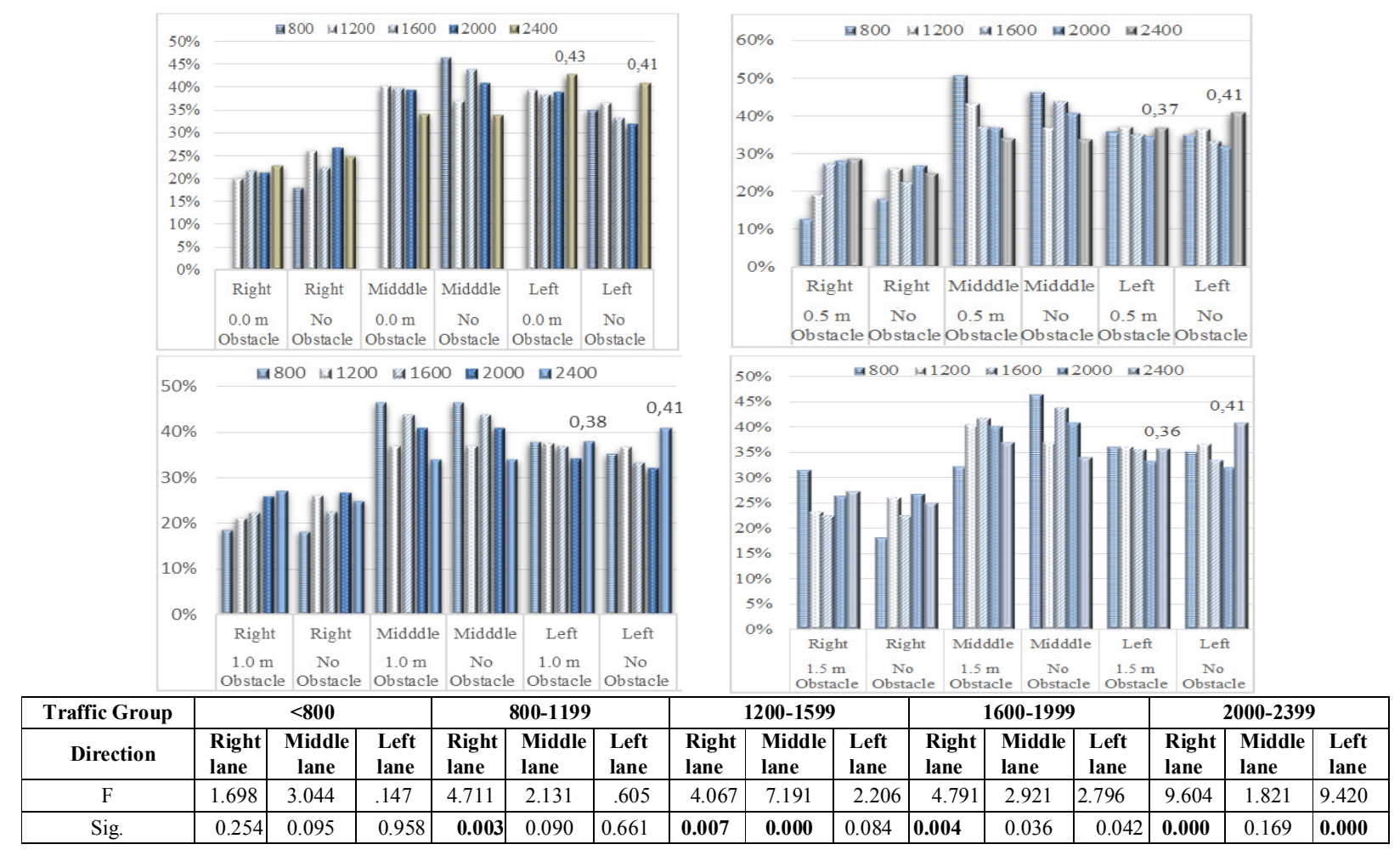

Fig. 3. Lane-use distribution function of lateral clearance and traffic flow rates

The use of the middle lane remains constant and the difference due to obstacle location is not statistically significant $(\mathrm{F}=0.691, \mathrm{P}=0.559)$. On the other hand, the left lane use decreases as the lateral clearance increases. The difference due to lateral clearance is statistically significant $(\mathrm{F}=5.259$, $\mathrm{P}=0.001)$. Figure 6 suggests that there is no difference in lane 
distribution between the case of lateral clearance of $1.5 \mathrm{~m}$ and the no obstacle case.

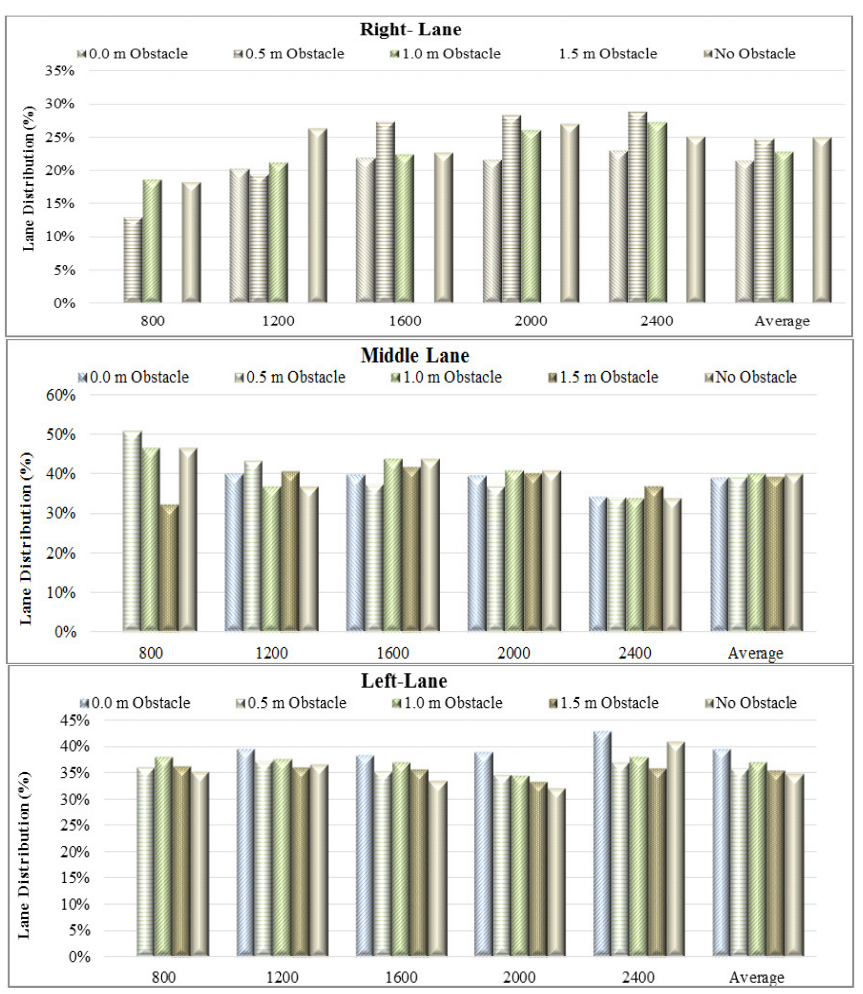

Fig. 4. Effect of lateral clearance on traffic flow rates

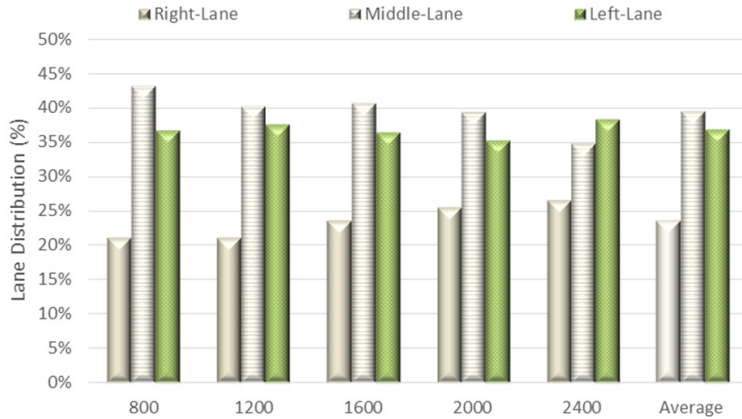

Fig. 5. Relationship of lane distribution vs traffic flow rates

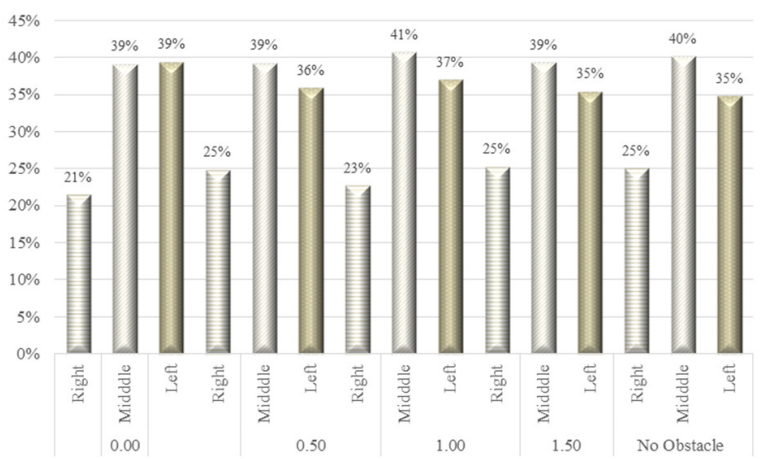

Fig. 6. Lane distribution function of lateral clearance "Obstacle Location"
Speed data clearly show that as the obstacle moved further from the carriageway edge, the speed begun to increase (Figure 7). The speed related to the no obstacle location is almost identical to that related to $1.5 \mathrm{~m}$ lateral clearance. Table II presents the paired-sample t-test used to investigate the speed differences between the no obstacle location and the lateral clearance under assessment. It shows that there is significant difference for all tested pairs that can be attributed to lateral clearance. There are significant speed differences between all tested pairs due to obstacle locations.

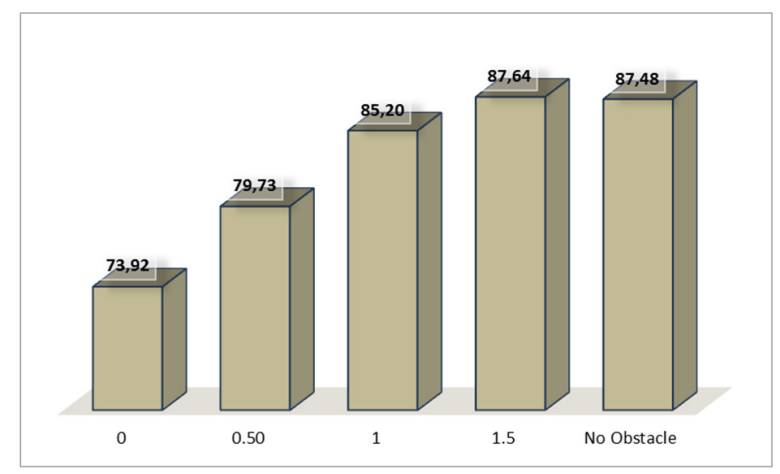

Fig. 7. Relationship between vehicle speed vs lateral clearance

TABLE II. PAIR-SAMPLE T-TEST: SPEED DIFFERENCES

\begin{tabular}{|c|c|c|c|c|c|c|c|c|}
\hline \multirow{2}{*}{$\begin{array}{c}\text { Obstacle location } \\
\text { vs no obstacle } \\
\text { case }\end{array}$} & Mean & \multirow{5}{*}{$\begin{array}{c}\text { Std. } \\
\text { dev. }\end{array}$} & $\begin{array}{c}\text { Std. } \\
\text { error } \\
\text { mean }\end{array}$ & $\begin{array}{c}\text { 95\% confidence } \\
\text { interval }\end{array}$ & t-value & dfa & Sigb \\
\cline { 4 - 10 }$n n n$ & & & Lower & Upper & & & \\
\hline vs zero distance & 13.28 & 5.78 & 0.52 & 12.26 & 14.30 & 25.67 & 124 & 0.00 \\
\hline vs $0.5 \mathrm{~m}$ distance & 6.79 & 3.13 & 0.29 & 6.22 & 7.36 & 23.56 & 117 & 0.00 \\
\hline vs $1.0 \mathrm{~m}$ distance & 6.37 & 4.57 & 0.41 & 5.56 & 7.18 & 15.58 & 124 & 0.00 \\
\hline vs $1.5 \mathrm{~m}$ distance & 6.13 & 4.01 & 0.36 & .5 .42 & 6.84 & 17.1 & 124 & 0.00 \\
\hline
\end{tabular}
df: degrees of freedom

\section{CONCLUSIONS}

This paper investigated the impact of placing obstacles on the right edge of the road's travel-lane (lateral clearance) on lane distribution and speed. Test sections were defined and obstacles were formed by placing a series of traffic cones on four different distances $(0.0,0.5,1.0$ and $1.5 \mathrm{~m})$. As a reference case, traffic parameters were also collected for a section with no obstacles. The analysis covers the change in lane distribution for different traffic flow rate for each obstacle location. The average traffic speed for each obstacle location was compared. Factors used in the analysis include obstacle location and traffic flow rate category $(<800,800-1199,1200$ $1599,1600-1999$ and 2000-2004 vehicles per hour). The results showed that lane distribution significantly depends on lateral clearance and traffic category. As obstacle distance measured from the carriageway edge increases, right-lane-use and leftlane-use increases while the middle-lane remains almost at the same level. Average speed increases as lateral clearance increase. The results also showed that average speed and lane distribution for the $1.5 \mathrm{~m}$ obstacle distances are very similar to 
the prevailing traffic parameters describing the no obstacle condition.

Regarding the impact of traffic flow rate on lane distribution, the results showed that, there is no significant difference in lane distribution due to obstacle location for each flow rate category with exceptions related to right-lane-use and left-lane use for high traffic flow rates (2000-2399veh/h hour). The main conclusions that can be drawn are that drivers tend to use the middle lane more than others. A small percentage of the drivers would select the right lane particularly with the presence of obstacles. This implies that the impact of lateral clearance is more profound and significant on the right lane. The use of the left-lane marginally fluctuates with significant increase if traffic flow rates reach high levels.

\section{REFERENCES}

[1] M. M. M. Abdel-Aal, A. E. A. El-Maaty, H. A. A. Samra, "Factors affecting road capacity under non-ideal conditions in Egypt", Nova Journal of Engineering and Applied Sciences, Vol. 7, No. 1, pp. 1-13, 2018

[2] M. R. Amin, J. H. Banks, "Variation in freeway lane flow patterns with volume, time of day, and location", Transportation Research Record, Vol. 1934, No. 1, pp. 132-139, 2005

[3] F. J. Breuer, B. Beckmann, "Geschwindigkeit und spurenbelegung auf autobahnen. Schriftenreihe stadt - region", Land des Institutes für Stadtbauwesen, Vol. 6, No 1969. RWTH Aachen, 1969 (in German)

[4] M. Ghasemian, S. Amini, M. Princevac, "The influence of roadside solid and vegetation barriers on near-road air quality", Atmospheric Environment, Vol. 170, pp. 108-117, 2017

[5] F. Hall, T. Lam, "The characteristics of congested flow on a freeway across lanes, space and time", Transportation Research A, Vol. 22, No. 3, pp. 45-56, 1988

[6] R. Hotop, "Untersuchung der Verkehrsqualitat auf zwei- und dreispurigen BAB", Richtungsfahrbahnen. Straßenverkehrstechnik, Vol. 19/1975, 1975 (in German)

[7] D. Heidemann, "Distribution of traffic to the individual lanes on multilane unidirectional roadways", Second International Symposium on Highway Capacity, Melbourne, Australia, 1994

[8] T. Jensen, "Weather and road capacity", Annual Transport Conference at Aalborg University, 2014

[9] J. Lee, B. Park, "Lane flow distributions on basic segments of freeways under different traffic conditions", 89th Annual Meeting of the Transportation Research Board, Washington, USA, January 10-14, 2010

[10] W. Leutzbach, F. Busch, Spurenwechselvorgange auf dreispurigen BAB-Richtungsfahrbahnen,. University of Karlruhe, 1984 (in German)

[11] A. Maurya, S. Das, S. Dey, S. Nama, "Study on speed and time-headway distributions on two-lane bidirectional road in heterogeneous traffic condition", Transportation Research Procedia, Vol. 17, pp. 428-437, 2016

[12] L. Putranto, N. Setyarini, "Vehicle composition and lane distribution in multilane highways in Indonesian cities", Procedia-Social and Behavioral Sciences, Vol. 16, pp. 374-381, 2011

[13] S. Samoili, A. G. Dumont, N. Geroliminis, "Dynamics of lane distribution flows in freeways", 13th Swiss Transport Research Conference, Monte Verita, Switzerland, April 24-26,2013

[14] U. Sparmann, "Spurwechselvorgange auf zweispurigen BAB Richtungsfahrbahnen", Forschung Straßenbau und Straßenverkehrstechnik, Vol. 263/1978, 1978 (in German)

[15] R. Tay, A. Churchill, "Effect of different median barriers on traffic speed", Canadian Journal of Transportation, Vol. 1, No. 1, pp. 56-66, 2007

[16] N. Wu, "Equilibrium of lane flow-distribution on motorways", Transportation Research Record, Vol. 1965, No. 1, pp. 48-59, 2006
[17] S. A. Arhin, A. Gatiba, "Predicting injury severity of angle crashes involving two vehicles at unsignalized intersections using artificial neural networks", Engineering, Technology \& Applied Science Research, Vol. 9, No. 2, pp. 3871-3880, 2019

[18] M. Touahmia, "Identification of risk factors influencing road traffic accidents", Engineering, Technology \& Applied Science Research, Vol. 8, No.1, pp. 2417-2421, 2018 